\title{
Announcements
}

Michael Prize 1984 Awarded to

Dr. Moshe and Dr. Noebels
International Symposium on Cavernous

Sinus (ISOCS)
Ljubljana, Yugoslavia, June 29 -July 3, 1986

The Michael Prize of 10,000 - DM for important contributions to research in the field of epileptology has been awarded in equal shares to Dr. Solomon $L$. Moshe of Albert Einstein College in New York and to Dr. Jeffrey $L$. Noebels of Harvard Medical School in Boston, Mass., USA.

The awarding ceremony took place during the opening session of the 16th Epilepsy International Congress in Hamburg on 6th September, 1985, in the Town Hall of Hamburg. After presenting the lauda-tiones of the two prize winners to the auditory by Professor Dr. Mogens Dam, President of the International League Against Epilepsy, Dr. Agathe Biihler, the daughter of the founder of the Michael Foundation, handed over the prize.

The principal aim of the Stiftung Michael is to fight epilepsy and its individual and social consequences.

For the first time offered in 1963 by the Stiftung Michael to stimulate epilepsy research in Germany the Michael Prize has by now become well-known far beyond Germany.

The 1985/86 prize will be biannual and will be awarded specially to younger scientists up to 35 years of age. The prize money will be of 20,000- DM. Are being considered manuscripts or publications in English or German of the years 1985/86, which should be submitted in three copies to the Stiftung Michael, Kar-thauserstr. 10, 5300 Bonn-1, FRG, before December 31, 1986.

Additional information can be obtained through Vinko V. Dolenc, MD, Department of Neurosurgery, University Medical Centre, Zaloska 7, 61105 Ljubljana, Yugoslavia.

\section{Second International rCBF Workshop}

Supetar, Yugoslavia September 29 - October 4, 1986

The Second International rCBF Workshop on the 'Impact of functional imaging in neurology and psychiatry| will be held in Supetar on the Island of Brae in Yugoslavia from September 29 to October 4, 1986. Inquiries: Dr. Stevo Knezevic, Department of Neurology, University Hospital Rebro, Kispaticeva 12, 41000 Zagreb (Yugoslavia) 